\title{
Recovery of Molybdenum and Rhenium Using Selective Precipitation Method from Molybdenite Roasting Dust in Alkali Leaching Solution
}

\author{
Sung-Ho Joo ${ }^{1,2}$, Young-Uk Kim ${ }^{1}$, Jin-Gu Kang ${ }^{2}$, Ho-Sung Yoon ${ }^{2}$, \\ Dong-Su Kim ${ }^{3}$ and Shun Myung Shin ${ }^{1,2, *}$ \\ ${ }^{1}$ Department of Resource Recycling, University of Science \& Technology (UST), Daejon 305-350, Korea \\ ${ }^{2}$ Metal Recovery Group, Mineral Resources Research Division, Korea Institute of Geoscience \& Mineral Resources (KIGAM), \\ Daejeon 305-350, Korea \\ ${ }^{3}$ Department of Environmental Science and Engineering, Ewha Womans University, Seoul 120-750, Korea
}

A study has been conducted for the separate recovery of molybdenum and rhenium from alkali leaching solution of molybdenite roasting dust by a selective precipitation method. Two kinds of synthetic alkali leaching solutions were employed and more than $85 \%$ of molybdenum was recovered as a precipitate in the experimental conditions of $243.15 \mathrm{~K}, \mathrm{pH} 2.2,200 \mathrm{rpm}$ of agitation speed, 7,200 s of reaction time, and 1.5 of equivalence ratio between $\mathrm{NH}_{4} \mathrm{OH}$ and $\mathrm{NaOH}$ for $\mathrm{NaOH}$ leaching solution. Regarding $\mathrm{NH}_{4} \mathrm{OH}$ leaching solution, the optimal conditions for the formation of molybdenum precipitate were found to be $243.15 \mathrm{~K}, \mathrm{pH} 2.5,100 \mathrm{rpm}$ of agitation speed, and $18,000 \mathrm{~s}$ of reaction time. The precipitation efficiency of molybdenum was higher than $99 \%$ in these conditions and molybdenum was observed to be precipitated as ammonium molybdate. Contrary to the precipitating behavior of molybdenum, rhenium was precipitated very little in the given conditions, which suggested a possibility for the selective recovery of molybdenum and rhenium. [doi:10.2320/matertrans.M2012209]

(Received June 11, 2012; Accepted August 27, 2012; Published October 11, 2012)

Keywords: molybdenite, precipitation method, ammonium molybdate, molybdenum, rhenium

\section{Introduction}

Rhenium does not exist as an elementary substance in the earth crust but it is finely compounded with other minerals in the amount of $0.1-10 \mathrm{mg} / \mathrm{dm}^{3}$. Among several minerals which contain rhenium in them, the content of rhenium in molybdenite $\left(\mathrm{MoS}_{2}\right)$ is usually higher than $20 \mathrm{mg} / \mathrm{dm}^{3}$, with the result that the by-products such as dust or waste liquid in the production process of molybdenum from molybdenite have become the major resource for rhenium production. Rhenium is mainly used as a raw material of the catalyst for the production of unleaded high-octane gasoline along with platinum and also employed as a component material of machine units such as a jet engine turbine blade after it is added to nickel and tungsten in a super alloy. Moreover, it is used as electric contacts in the electrical and electronic industries based on its peculiar property of increased electrical conductivity when it is alloyed with molybdenum and its utilization can be also found as a component in filaments and thermocouples due to its high heat-resistance. ${ }^{1,2)}$

The base mineral raw materials for recovery of rhenium are solid and liquid by-products of molybdenum, copper, lead and uranium production. Therefore, the recovery of rhenium from them is usually carried out by a hydrometallurgical process. ${ }^{3-6)}$ The hydrometallurgical process for the production of rhenium from the related by-products can be divided into two major successive processes, which are leaching process and recovery process. In the leaching process, the dissolution of rhenium is fulfilled from the resources and for this purpose several methods are presently being applied; process using sulfuric acid or nitric acid in the presence of various oxidants such as $\mathrm{O}_{3}, \mathrm{H}_{2} \mathrm{O}_{2}$ and $\mathrm{MnO}_{2}$, high-pressure process using an autoclave, and microbiological process. ${ }^{7,8)}$ However, all these processes have inherent demerits such as

*Corresponding author, E-mail: shin1016@kigam.re.kr the need of using additional oxidants for increased leaching efficiency, the request for employing high-priced equipment, and long time required for leaching. Therefore, it is necessary to develop a new way of a hydrometallurgical process which is economical and rapid for the separation and recovery of rhenium from the industrial by-products containing rhenium. In this study, based on the fact that rhenium can exist in the ionic form of $\mathrm{ReO}_{4}{ }^{-}$in all $\mathrm{pH}$ region a selective precipitation method was investigated from the alkali leaching solution of molybdenite roasting dust for effective separation and recovery of rhenium and molybdenum.

\section{Experimental}

\subsection{Materials}

A synthetic alkali leaching solution was employed in the experiment to maintain the consistency of study. The leaching solution was prepared by adding desired amounts of rhenium powder ( $>99.9 \%$, Aldrich), sodium molybdate (>99.0\%, Samchun), calcium chloride (>99.0\%, Junsei), sodium aluminate ( $>99.0 \%$, Samchun) and copper chloride ( $>99.0 \%$, Junsei) to $\mathrm{NaOH}$ solution. The composition of the synthesized $\mathrm{NaOH}$ leaching solution is shown in Table 1.

Another synthetic alkali leaching solution was prepared using $\mathrm{NH}_{4} \mathrm{OH}$ solution. Rhenium powder (>99.9\%, Aldrich), ammonium molybdate ( $>99.0 \%$, Samchun), calcium sulfate ( $>99.0 \%$, Junsei), aluminum sulfate $(57.5 \%$, Samchum) and copper sulfate $\left(>99.0 \%\right.$, Junsei) were added to $\mathrm{NH}_{4} \mathrm{OH}$ solution in their desired amounts and its composition is presented in Table 2.

Table 1 Chemical composition of the $\mathrm{NaOH}$ leaching solution.

\begin{tabular}{cccccc}
\hline Element & $\mathrm{Re}$ & $\mathrm{Mo}$ & $\mathrm{Cu}$ & $\mathrm{Ca}$ & $\mathrm{Al}$ \\
\hline $\mathrm{mg} / \mathrm{dm}^{3}$ & 207 & 25450 & 13 & 2 & 680 \\
\hline
\end{tabular}


Table 2 Chemical composition of the $\mathrm{NH}_{4} \mathrm{OH}$ leaching solution.

\begin{tabular}{cccccc}
\hline Element & $\mathrm{Re}$ & $\mathrm{Mo}$ & $\mathrm{Cu}$ & $\mathrm{Ca}$ & $\mathrm{Al}$ \\
\hline $\mathrm{mg} / \mathrm{dm}^{3}$ & 173 & 22100 & 29 & 4 & 580 \\
\hline
\end{tabular}

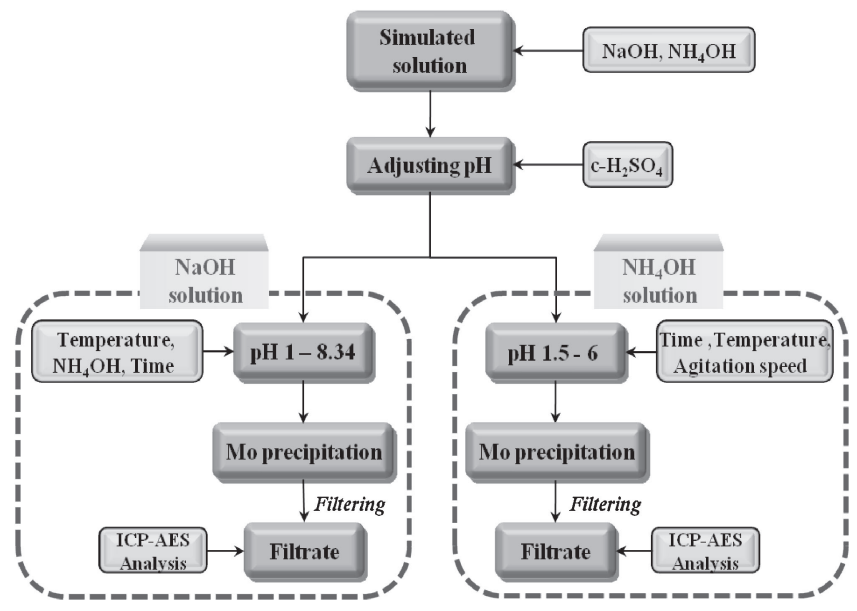

Fig. 1 Flowsheet of the precipitation test for two synthetic leaching solutions.

\subsection{Procedures and analyses}

The precipitating behavior of molybdenum was investigated using two synthetic leaching solutions. The volume of the reactor was 1 liter and the reaction temperature was controlled by a temperature regulator while it was monitored using a thermometer which was attached to a hot plate. The solution was continuously stirred with a magnetic bar while the precipitation reaction proceeded. For $\mathrm{NaOH}$ leaching solution, the solution $\mathrm{pH}$ was adjusted to 1 with $\mathrm{H}_{2} \mathrm{SO}_{4}$ and after the equivalence ratio of $\mathrm{NH}_{4} \mathrm{OH}$ to $\mathrm{NaOH}$ was adjusted to a desired value it was heated at a certain temperature for a given period. After the precipitation reaction was completed, the precipitating behavior of rhenium and molybdenum was examined by analyzing the filtrate with an ICP-AES (Shimadzu: Model No. ICPS-7500). For $\mathrm{NH}_{4} \mathrm{OH}$ leaching solution, the solution $\mathrm{pH}$ was adjusted in the range of 1.5-6.0 and reaction temperature was changed from 303 to $343 \mathrm{~K}$ while the agitation speed of solution was varied between $100-400 \mathrm{rpm}$. Through the analysis of filtrate by ICP-AES, the precipitation characteristics of molybdenum and rhenium were figured out. Figure 1 shows the experimental procedures of the precipitation test for the two leaching solutions.

\section{Results and Discussion}

\subsection{Precipitation of molybdenum in $\mathrm{NaOH}$ leaching solution}

Prior to the precipitation test, the possibility of the leaching out of rhenium and molybdenum from molybdenite roasting dust in $\mathrm{NaOH}$ solution was examined based on thermodynamic estimation. The chemical reactions which can take place when rhenium and molybdenum are leached out from their oxides in $\mathrm{NaOH}$ solution are presumably suggested as follows; (a)

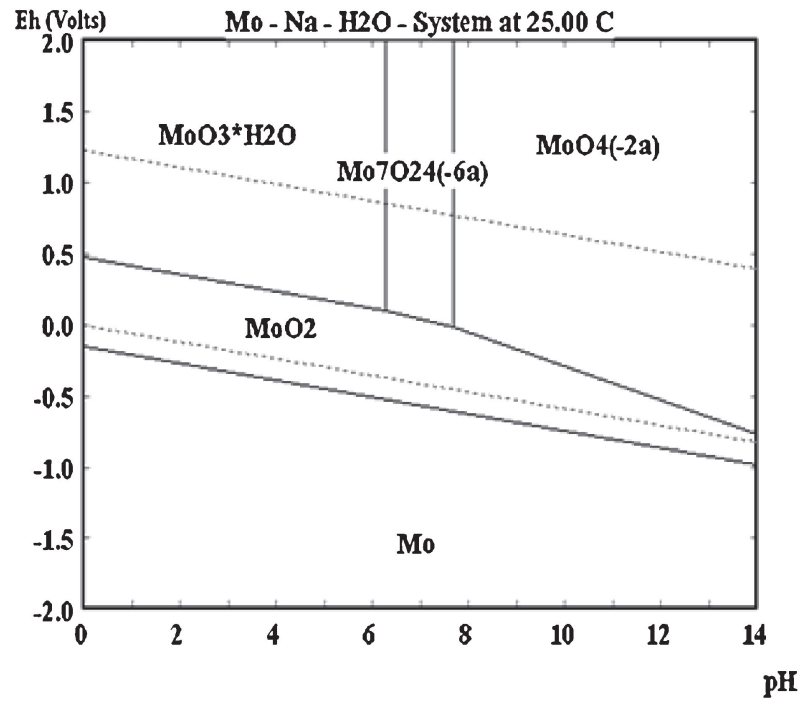

(b)

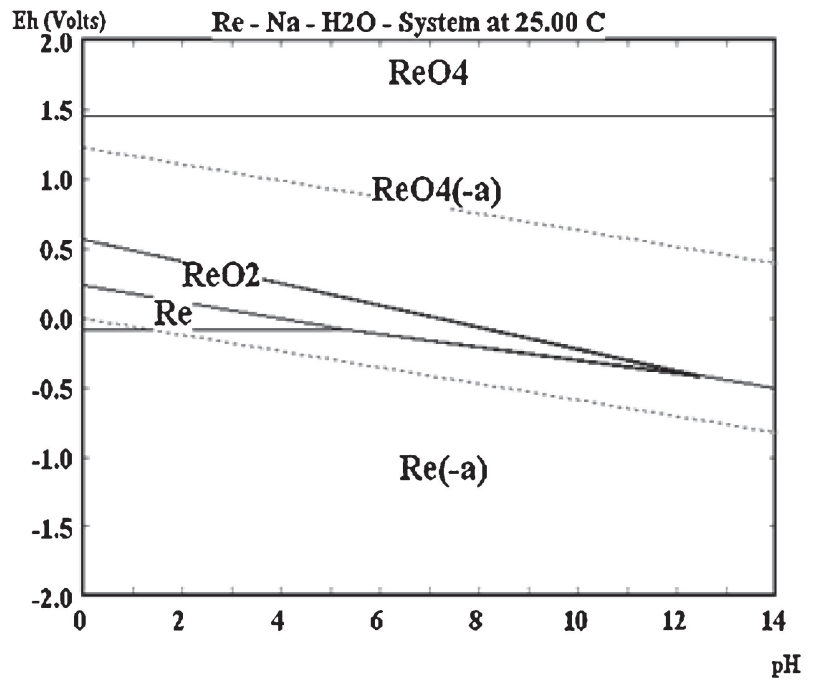

Fig. 2 Eh-pH diagrams of molybdenum and rhenium in $\mathrm{Na}-\mathrm{H}_{2} \mathrm{O}$ system (-a; anion): (a) Mo-Na- $\mathrm{H}_{2} \mathrm{O}$ system, (b) $\mathrm{Re}-\mathrm{Na}-\mathrm{H}_{2} \mathrm{O}$ system.

$$
\begin{aligned}
& \mathrm{ReO}_{2}+\mathrm{NaOH}+3 / 4 \mathrm{O}_{2} \rightleftharpoons \mathrm{Na}^{+}+\mathrm{ReO}_{4}{ }^{-}+1 / 2 \mathrm{H}_{2} \mathrm{O} \\
& \quad\left(\Delta G^{0}=-74.5 \mathrm{kcal} / \mathrm{mol}\right) \\
& \mathrm{ReO}_{3}+\mathrm{NaOH}+1 / 4 \mathrm{O}_{2} \rightleftharpoons \mathrm{Na}^{+}+\mathrm{ReO}_{4}{ }^{-}+1 / 2 \mathrm{H}_{2} \mathrm{O} \\
& \quad\left(\Delta G^{0}=-45.0 \mathrm{kcal} / \mathrm{mol}\right) \\
& \mathrm{ReO}_{4}+\mathrm{NaOH} \rightleftharpoons \mathrm{Na}^{+}+\mathrm{ReO}_{4}{ }^{-}+1 / 2 \mathrm{H}_{2} \mathrm{O}+1 / 4 \mathrm{O}_{2} \\
& \quad\left(\Delta G^{0}=-33.4 \mathrm{kcal} / \mathrm{mol}\right) \\
& \operatorname{Re}_{2} \mathrm{O}_{3}+2 \mathrm{NaOH}+2 \mathrm{O}_{2} \rightleftharpoons 2 \mathrm{Na}^{+}+2 \mathrm{ReO}_{4}{ }^{-}+\mathrm{H}_{2} \mathrm{O} \\
& \quad\left(\Delta G^{0}=-230.8 \mathrm{kcal} / \mathrm{mol}\right) \\
& \operatorname{Re}_{2} \mathrm{O}_{7}+2 \mathrm{NaOH} \rightleftharpoons 2 \mathrm{Na}+2 \mathrm{ReO}_{4}^{-}+\mathrm{H}_{2} \mathrm{O} \\
& \quad\left(\Delta G^{0}=-72.2 \mathrm{kcal} / \mathrm{mol}\right)
\end{aligned}
$$

According to the suggested reactions, the rhenium oxides which existing in the molybdenite roasting dust are expected to be changed into $\mathrm{ReO}_{4}{ }^{-}$by $\mathrm{NaOH}$. The Eh-pH diagrams of molybdenum and rhenium were constructed using thermodynamic data (Fig. 2) and applied to the understanding of the feasibilities of their leaching out based on the chemical species which subsist at each potential and $\mathrm{pH}$ condition. 
Table 3 Chemical compositions of the initial solution, filtrate and precipitate $\left(\mathrm{mg} / \mathrm{dm}^{3}\right)$.

\begin{tabular}{lcccc}
\hline \multirow{2}{*}{ Type } & $\mathrm{Re}$ & $\mathrm{Mo}$ & $\mathrm{Cu}$ & $\mathrm{Al}$ \\
\cline { 2 - 5 } & 209 & 26200 & 12 & 640 \\
\hline Initial solution & 174.8 & 14630 & 6.6 & 180 \\
Filtrate & - & 12200 & 3 & 450 \\
Precipitate & - &
\end{tabular}

Table 4 Variation of the solution composition with the equivalence ratio between $\mathrm{NH}_{4} \mathrm{OH}$ and $\mathrm{NaOH}\left(\mathrm{mg} / \mathrm{dm}^{3}\right)$.

\begin{tabular}{cccccc}
\hline \multirow{2}{*}{ Equivalence ratio } & \multicolumn{5}{c}{ Element } \\
\cline { 2 - 5 } & $\mathrm{Re}$ & $\mathrm{Mo}$ & $\mathrm{Cu}$ & $\mathrm{Al}$ & $\mathrm{pH}$ \\
\hline Initial solution & 206.5 & 25450 & 13 & 680 & 1.00 \\
0.5 & 186 & 26200 & $<1$ & 570 & 1.33 \\
1.0 & 184 & 24700 & $<1$ & 540 & 1.58 \\
1.5 & 175 & 3900 & $<1$ & 18 & 2.20 \\
2.0 & 166 & 14500 & $<1$ & 250 & 6.17 \\
2.5 & 172 & 24800 & $<1$ & 520 & 8.15 \\
3.0 & 177 & 24700 & $<1$ & 550 & 8.34 \\
\hline
\end{tabular}

The possibility of the precipitation of molybdenum was investigated using $\mathrm{NaOH}$ leaching solution whose $\mathrm{pH}$ was controlled to 1 . A preliminary test was carried out employing $50 \mathrm{~cm}^{3}$ of artificial leaching solution which was heated to $343.15 \mathrm{~K}$ and it was verified that a precipitate was formed in the solution. The chemical composition of the obtained precipitate was analyzed and presented in Table 3 along with the analytical result for the compositions of the leaching solution and filtrate.

As shown in Table 3, it was possible for molybdenum to be precipitated out in the leaching solution and rhenium was observed not to exist in the precipitate. However, the precipitation reaction of molybdenum was regarded to be not effective solely based on its solubility characteristics. Therefore, an experimental scheme was contrived that the molybdenum is precipitated in the form of chemical compound by adding $\mathrm{NH}_{4} \mathrm{OH}$ to $\mathrm{NaOH}$ leaching solution. Table 4 shows the change of the solution composition according to the equivalence ratio of $\mathrm{NH}_{4} \mathrm{OH}$ and $\mathrm{NaOH}$ when the precipitation reaction proceeded for $2 \mathrm{~h}$ in the conditions of $343.15 \mathrm{~K}$ and $300 \mathrm{rpm}$.

As can be seen in Table 4, more than $85 \%$ of molybdenum and aluminium were found to be precipitated at 1.5 of equivalence ratio of $\mathrm{NH}_{4} \mathrm{OH}$ and $\mathrm{NaOH}$. Also, the concentration of rhenium varied with the equivalence ratio, which was probably due to its adsorption on the molybdenum precipitate. Figure 3 shows the variation of the precipitation efficiencies of molybdenum and aluminium and the change of solution $\mathrm{pH}$ with the equivalence ratio between $\mathrm{NH}_{4} \mathrm{OH}$ and $\mathrm{NaOH}$. The precipitation efficiency of molybdenum was decreased significantly above $\mathrm{pH} 2.5$ so that the $\mathrm{pH}$ range where molybdenum precipitated efficiently was found to be around 2-2.5. The precipitation efficiency of molybdenum reached $85 \%$ in the conditions of $343.15 \mathrm{~K}, \mathrm{pH} 2.2$, and 1.5 of equivalence ratio.

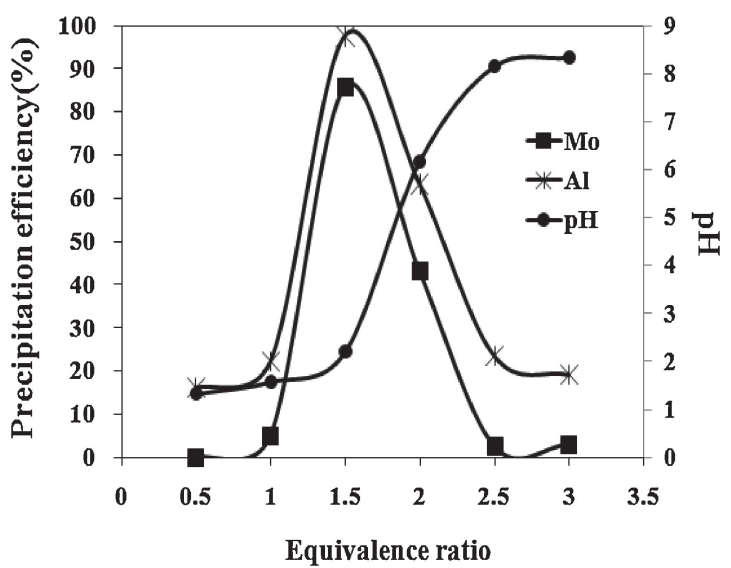

Fig. 3 Change of the precipitation efficiencies of molybdenum and aluminium and the $\mathrm{pH}$ of solution according to the equivalence ratio of $\mathrm{NH}_{4} \mathrm{OH}$ and $\mathrm{NaOH}$.

\subsection{Precipitation of molybdenum in $\mathrm{NH}_{4} \mathrm{OH}$ leaching solution}

Considering that $\mathrm{NH}_{4} \mathrm{OH}$ solution can be potentially applicable to the leaching of rhenium and molybdenum, the precipitating behavior of rhenium and molybdenum was investigated employing a synthetic $\mathrm{NH}_{4} \mathrm{OH}$ leaching solution. A preliminary test was conducted in the conditions

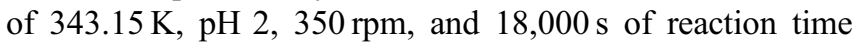
using $500 \mathrm{~cm}^{3}$ of solution for the verification of the formation of molybdenum precipitate and as a result about $60 \%$ of molybdenum was examined to be precipitated. The precipitate which was formed in $\mathrm{NH}_{4} \mathrm{OH}$ leaching solution was analyzed by XRD (Rigaku: Model No. Ru-200B) and it was found that the precipitate was $\left(\mathrm{NH}_{4}\right)_{2} \mathrm{Mo}_{4} \mathrm{O}_{13}$ (Fig. 4). The reason for the formation of crystalline ammonium molybdate in the precipitate forming reaction was understood to be due to the fact that polyanions such as $\mathrm{Mo}_{6} \mathrm{O}_{13}{ }^{2-}$ and $\mathrm{Mo}_{6} \mathrm{O}_{20}{ }^{4-}$ are generated when $\mathrm{MoO}_{3}$ is dissolved in the solution of pH 2-6 and these anions are subsequently polymerized by reacting with $\mathrm{NH}_{4}{ }^{+}$.

\subsection{Effect of reaction time}

Figure 5 shows the change of the precipitation efficiencies of each element according to the retention time when the precipitation reaction was progressed in the conditions of $343.15 \mathrm{~K}, \mathrm{pH} 6$, and $300 \mathrm{rpm}$ of agitation speed. As can be seen from the result, the equilibrium was nearly reached in $18,000 \mathrm{~s}$ after the reaction was started and more than $96 \%$ of molybdenum was observed to be precipitated in equilibrium. Therefore, the optimal reaction time for the formation of molybdenum precipitate was considered to around $5 \mathrm{~h}$ in the experimental conditions. Unlike molybdenum, almost no rhenium was precipitated during the entire reaction time in the given conditions.

\subsection{Effect of $\mathrm{pH}$}

The effect of $\mathrm{pH}$ on the precipitation efficiencies of molybdenum, rhenium, and aluminium was investigated in the conditions of $343 \mathrm{~K}$ and $300 \mathrm{rpm}$ (Fig. 6). The precipitation efficiency of molybdenum reached up to $99 \%$ around $\mathrm{pH} 2.5$ and it was decreased above and below this $\mathrm{pH}$. 


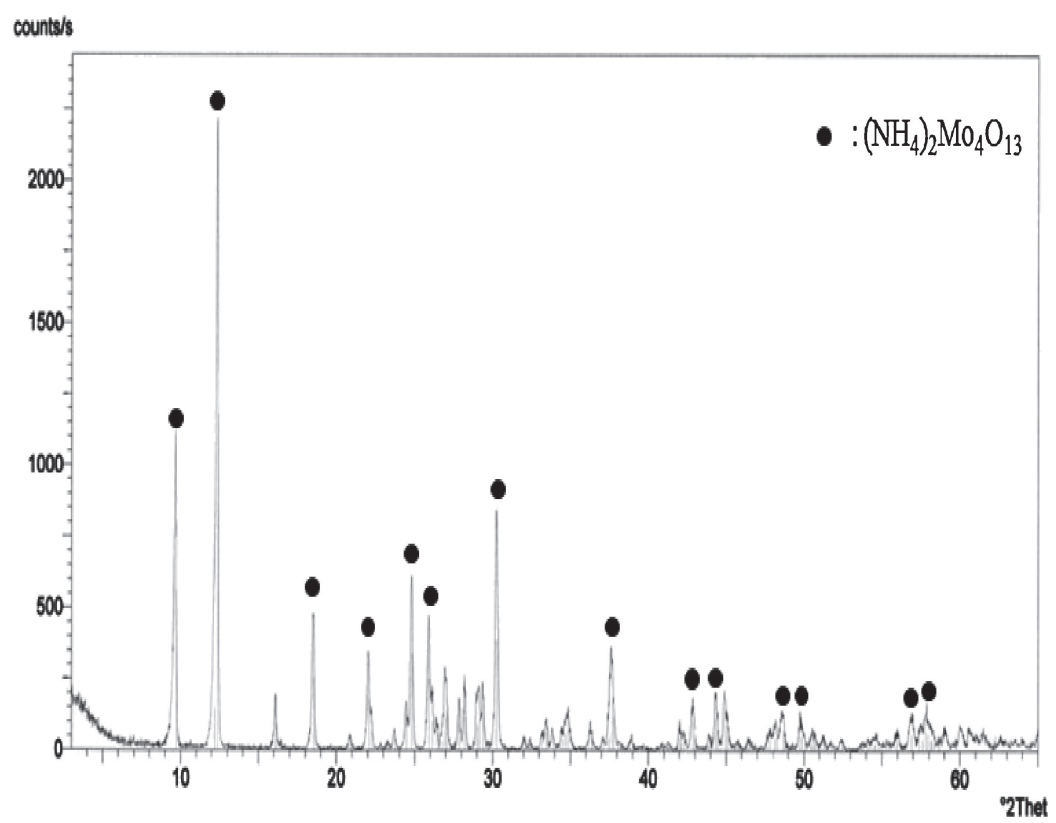

Fig. 4 XRD pattern of the precipitate formed in $\mathrm{NH}_{4} \mathrm{OH}$ leaching solution.

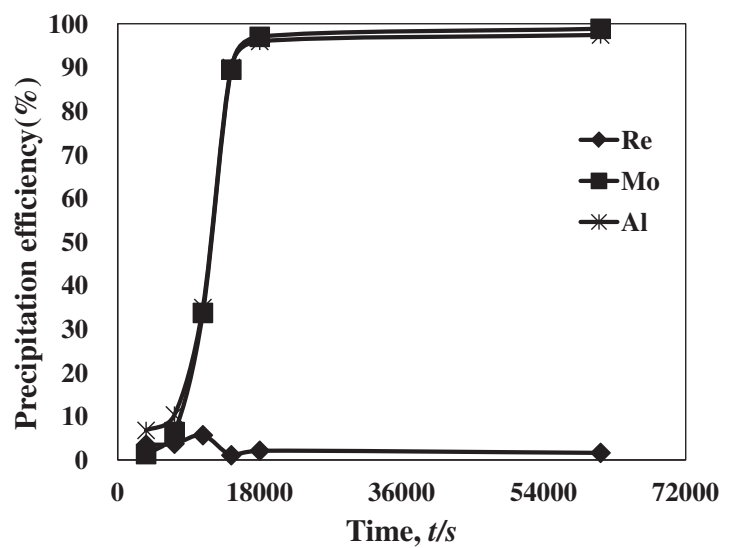

Fig. 5 Variation of the precipitation efficiencies of molybdenum, rhenium and aluminium with reaction time.

Therefore, the most appropriate $\mathrm{pH}$ condition for the recovery of molybdenum as a precipitate was found to be ca. $\mathrm{pH} 2.5$.

\subsection{Effect of reaction temperature}

Figure 7 shows the variation of the precipitation efficiencies of each element with reaction temperature when the precipitate forming experiment was carried out in the conditions of $\mathrm{pH} 2.5,300 \mathrm{rpm}$, and $18,000 \mathrm{~s}$ of reaction time. The precipitation efficiency of molybdenum was observed to increase with temperature and reached almost $99 \%$ at $343.15 \mathrm{~K}$, which was considered to be a pertinent thermal condition for a high recovery of molybdenum.

\subsection{Effect of agitation intensity}

The influence of agitation intensity on the precipitation efficiencies of each element was examined in the conditions of $343 \mathrm{~K}, \mathrm{pH} 2.5$, and $18000 \mathrm{~s}$ of reaction time. Figure 8 shows that there was almost no difference in the precipitation efficiency of molybdenum even if the agitation intensity

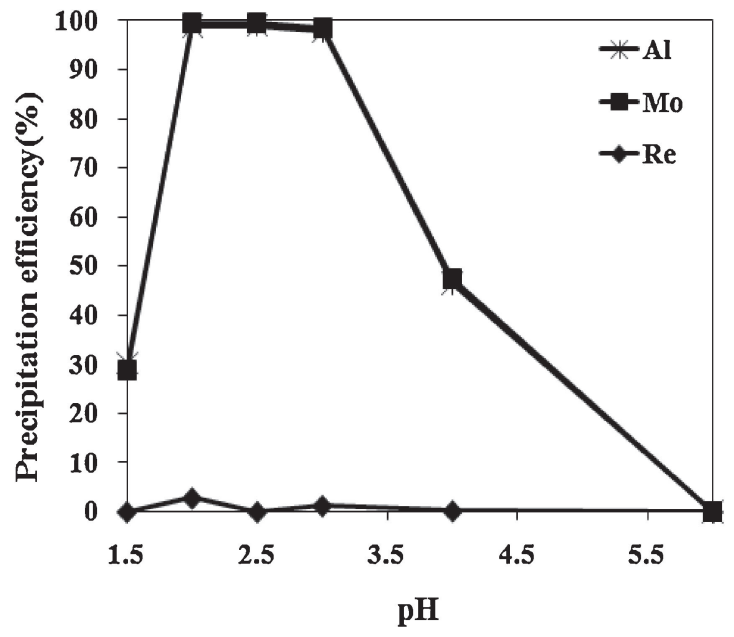

Fig. 6 Variation of the precipitation efficiencies of molybdenum, rhenium and aluminium with $\mathrm{pH}$.

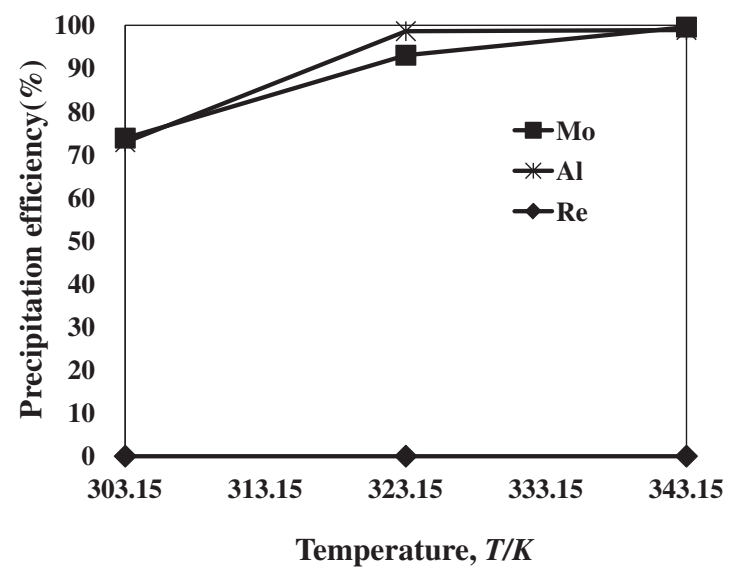

Fig. 7 Change of the precipitation efficiencies of each element according to the reaction temperature. 


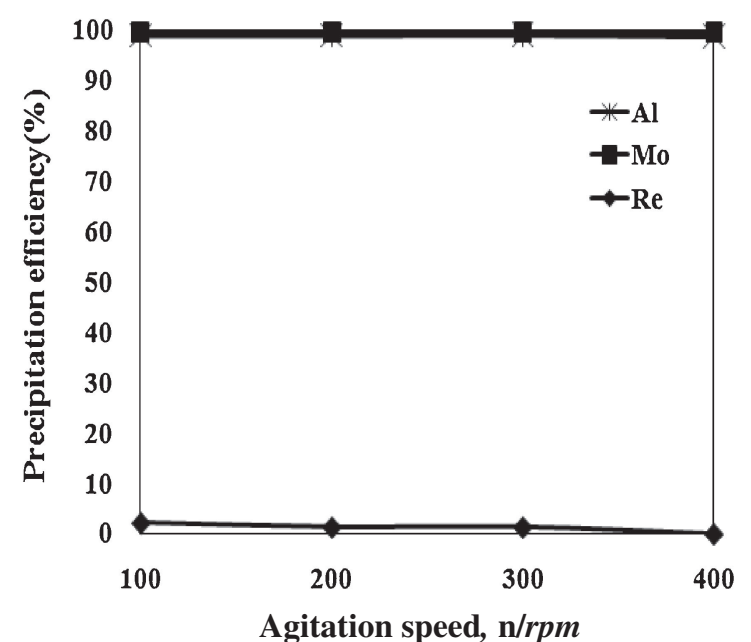

Fig. 8 Change of the precipitation efficiencies of each element according to the agitation speed.

was varied within the experimental conditions. Thus, lower agitation speed was thought to be better within the investigated conditions for the formation of molybdenum precipitate from the viewpoint of energy saving.

In the suggested experimental results, it was found that the precipitating behavior of aluminium was very similar to that of molybdenum, which is presumably due to the influence of molybdenum on the reactivity of aluminium in aquatic environment. However, the reason for this is not clear presently and further study will be necessary for its verification.

\section{Conclusions}

The feasibility of the separation and recovery of molybdenum and rhenium from molybdenite roasting dust by selective precipitation method was investigated employing two synthetic alkali leaching solutions. For $\mathrm{NaOH}$ leaching solution, molybdenum was observed to be precipitated by $85 \%$ in the conditions of $343.15 \mathrm{~K}, \mathrm{pH} 2.2,200 \mathrm{rpm}, 7,200 \mathrm{~s}$ of reaction time, and 1.5 of equivalence ratio of $\mathrm{NH}_{4} \mathrm{OH}$ and $\mathrm{NaOH}$. With regard to $\mathrm{NH}_{4} \mathrm{OH}$ leaching solution, the optimal conditions for the formation of molybdenum precipitate were found to be $343.15 \mathrm{~K}, \mathrm{pH} 2.5,100 \mathrm{rpm}$, and $18,000 \mathrm{~s}$ of reaction time within the experimental conditions. The precipitation efficiency of molybdenum was as high as $99 \%$ in these conditions and molybdenum was found to be precipitated in the form of ammonium molybdate. Unlike molybdenum, very little amount of rhenium was precipitated in the given conditions since rhenium exists as ionic forms in the $\mathrm{pH}$ range of $0-11$ except the Eh region between $0-0.4 \mathrm{~V}$.

\section{Acknowledgments}

This research was supported by the Basic Research Project (12-3111-1) of the Korea Institute of Geoscience and Mineral Resources (KIGAM) funded by the Ministry of Knowledge Economy of Korea.

\section{REFERENCES}

1) Z. S. Abisheva, A. N. Zagorodnyaya and N. S. Bekturganov: Hydrometallurgy 109 (2011) 1-8.

2) A. Amer: Erzmetall. 54 (2001) 381-385.

3) Z. S. Abisheva and A. N. Zagorodnyaya: Hydrometallurgy 63 (2002) 55-63.

4) S. K. Kalinin and E. E. Fain: Izv. AN KazSSR: Series Geol. 6 (1977) $1-7$.

5) Z. S. Abisheva, A. N. Zagorodnyaya, A. S. Sharipova, T. N. Bukurov, K. D. Teleshev and A. B. Yudin: Tsvetnye Metally 1 (2004) 30-35.

6) A. N. Zagorodnyaya and Z. S. Abisheva: Hydrometallurgy 65 (2002) 69-76.

7) F. Sh. Balgaeva and A. S. Medvedev: Russ. J. Non-Ferrous Metals 48 (2007) 107-109.

8) M. A. Askari Zamani, N. Hiroyoshi, M. Tsunekawa, R. Vaghar and M. Oliazadeh: Hydrometallurgy 80 (2005) 23-31. 